\title{
COVID-19 Awakening: Preparedness, Readiness and Response during the pandemic
}

\author{
Daniel W Kitua ${ }^{\mathrm{a}}$, Andrew Y Kitua ${ }^{\mathrm{b}, \mathrm{c}}$ \\ ${ }^{a}$ Faculty of Medicine, Muhimbili University of Health and Allied Sciences, Dar-es-Salaam, Tanzania \\ ${ }^{\mathrm{b}}$ Public Health and Environmental Advancement Interventions - NGO "NGALAKERI", Morogoro, Tanzania; ${ }^{\mathrm{c}}$ National Institute for Medical Research, Tanzania \\ *Correspondence to Daniel W. Kitua (deekitua@hotmail.com)
}

\begin{abstract}
At the end of December 2019, the China public health authorities were informed on cases of unusual pneumonia detected in Wuhan City, mainland China. The causative agent was later identified to be a novel coronavirus (2019-nCoV) currently referred to as the severe acute respiratory syndrome coronavirus 2 (SARS CoV-2). The World Health Organization declared the disease a public health emergency of international concern on $30^{\text {th }}$ January 2020 and named it Coronavirus disease 2019 (COVID-19) on $11^{\text {th }}$ February 2020. By 20 ${ }^{\text {th }}$ April 2020, over 2.4 million cases of COVID-19 had been reported from 210 countries and territories worldwide. The rate at which COVID-19 spreads and the fact that asymptomatic individuals can transmit the disease has risen concerns on how to control the pandemic in resource-constrained countries. We conducted a review of literatures and summarized the key lessons to inform policy and decision makers on strategies necessary for an effective response during the pandemic. We recommend comprehensive implementation of the proposed approaches that encompass robust containment strategies and flexible transition to scaling up mitigation strategies.
\end{abstract}

Key words: Preparedness and Response, SARS CoV-2, COVID-19, Pandemic, Epidemic, Outbreak.

\section{INTRODUCTION}

andemics have appeared to be increasing in frequency acute respiratory syndrome coronavirus (SARS-CoV) epidemic that started in Guangdong province southern China, spreading across 26 countries and affecting over 8000 people, the world has experience at least 10 major outbreaks including the 2014-2016 Ebola outbreak in West Africa that claimed over 11,000 lives ${ }^{1-3}$. On $31^{\text {st }}$ December 2019, the World Health Organization (WHO) China Country Office was notified of unusual cases of acute respiratory syndrome in Wuhan City, Hubei province, China. On 7th January the causative agent was identified to be a novel coronavirus (2019-nCoV), currently referred to as the severe acute respiratory syndrome coronavirus 2 (SARS-CoV-2) ${ }^{4}$. The World Health Organization (WHO) declared the disease a public health emergency of international concern on $30^{\text {th }}$ January 2020 and named it Coronavirus disease 2019 (COVID-19) on $11^{\text {th }}$ February 2020. By $20^{\text {th }}$ April 2020, the COVID-19 pandemic had spread across 210 countries and territories, affecting over 2.4 million people and causing more than 160,000 deaths worldwide ${ }^{5}$. Its estimated global case fatality rate is $3.4 \%$, but higher rates of up to $6.16 \%$ and
9.26\% have been reported in Spain and Italy respectively ${ }^{6,7}$. At least 600 confirmed COVID-19 cases and over 20 related deaths have already been reported from 6 member States of The East African Community (EAC) as seen in Figure 1 and Figure $2^{5}$ as of $19^{\text {th }}$ April 2020. It has been demonstrated that the type of outbreaks and response measures taken against them can determine the level of social and economic disruption, political stresses and tensions, violence and even changes in individual behaviors ${ }^{8}$.

A comprehensive outbreak response is a complex multifaceted systematic plan that has to be harmoniously coordinated. We have observed concerns on how to apply knowledge about infection prevention and the control of the pandemic especially in resource-constrained countries ${ }^{9}$. In order to address this concern, we reviewed relevant articles of interest after conducting an online literature search through PubMed, Google Scholar and the World Wide Web using the keywords: '2019-nCoV', 'SARS CoV-2', 'COVID-19 Preparedness and Response"; 'Pandemic/outbreak/epidemic containment and Mitigation', ''Screening', 'Sensitivity', 'Specificity", and 'Predictive values"' in different combinations. 
In this article, we provide an overview to policy and decision makers; enlightening the understanding on the spectrum of activities necessary for effective response against the COVID-19 outbreak by using two different models of approach. We also provide suggestions on different screening approaches that may be applied with respect to the dynamics of an outbreak. This will help in providing guidance on how to respond to both the current and future outbreaks.

\section{FIGURE 1. The cumulative frequency of confirmed COVID-19 cases in EAC member states over time}

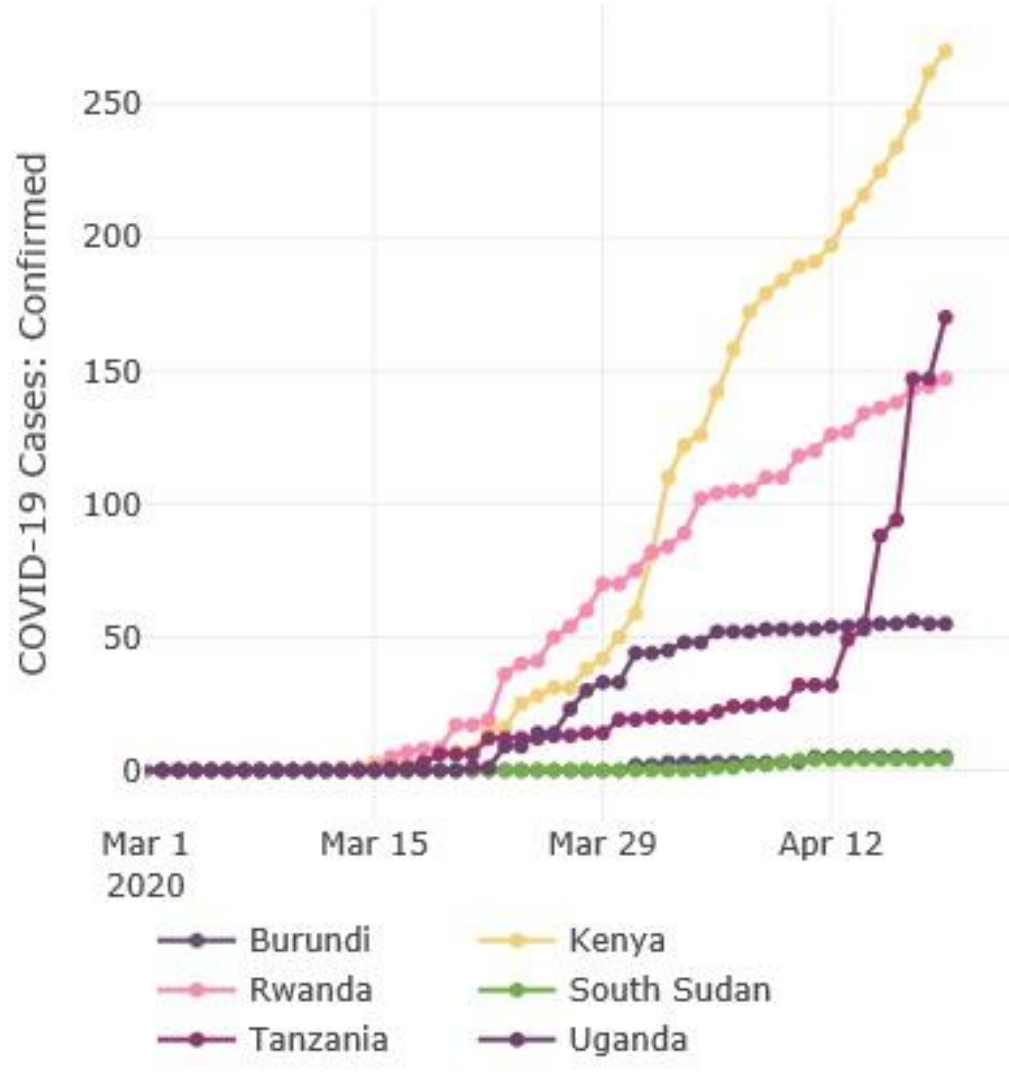

Adopted from: The World Bank Group. Understanding the Coronavirus (COVID-19) pandemic through data | Universal Health Coverage Data | World Bank. Datatopics.worldbank.org. http://datatopics.worldbank.org/universal-healthcoverage/covid19/. Published 2020. Accessed April 20, 2020 


\section{FIGURE 2. The cumulative frequency of COVID-19 related deaths in EAC member states overt time}

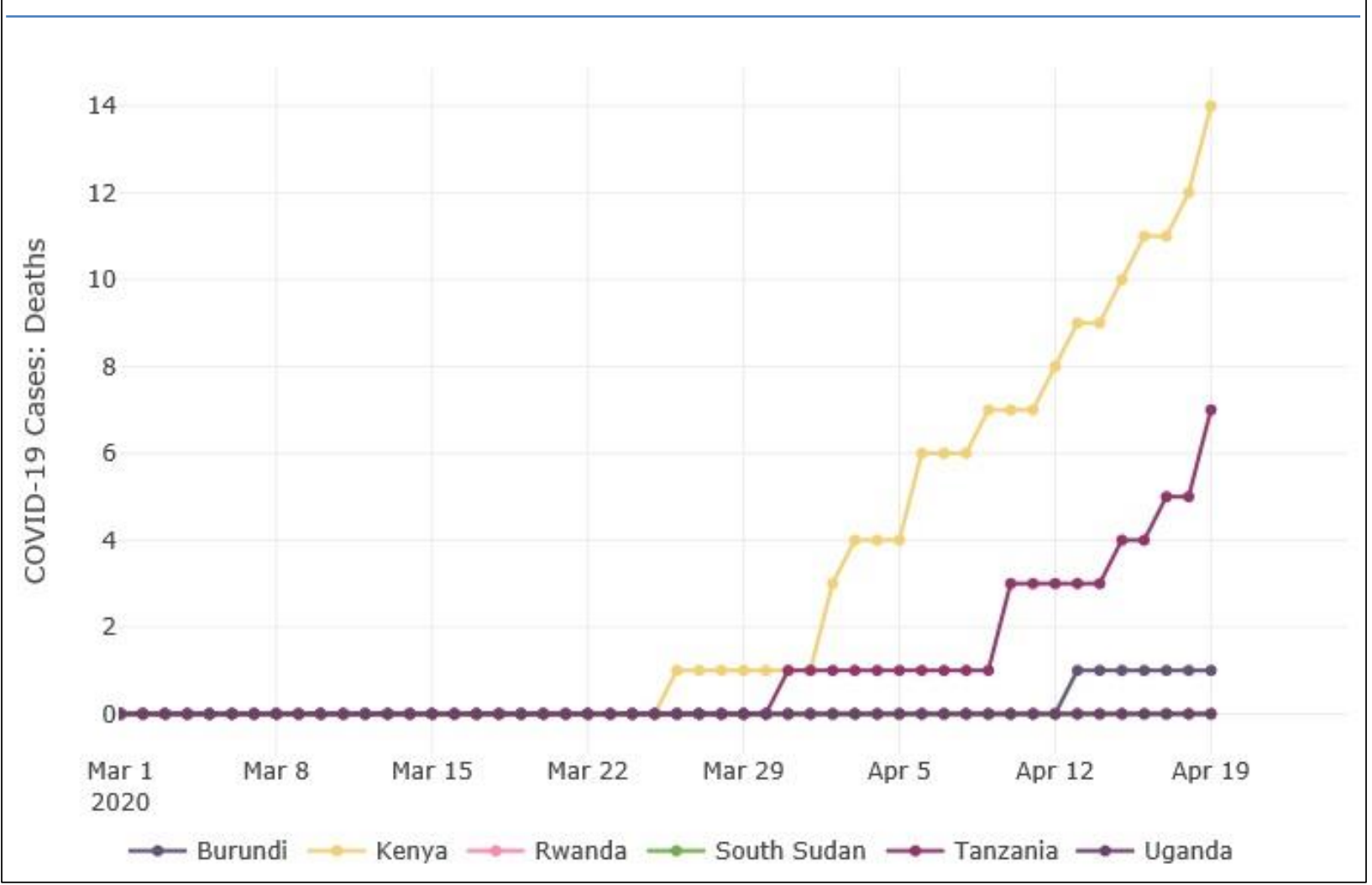

Adopted from: The World Bank Group. Understanding the Coronavirus (COVID-19) pandemic through data | Universal Health Coverage Data | World Bank. Datatopics.worldbank.org. http://datatopics.worldbank.org/universal-healthcoverage/covid19/. Published 2020. Accessed April 20, 2020.

\section{UNDERSTANDING THE RESPONSE} APPROACH TO AN OUTBREAK

Effective preparedness against health threats is essential for a robust and sustained response during an outbreak. Such kind of preparedness will require adequate investment to strengthen the existing health care systems ${ }^{10}$. Controlling the spread of highly transmissible diseases like COVID-19 require swift mobilization of personnel and resources in order to rapidly implement effective interventions capable of preventing the devastating impacts that are likely to result from a pandemic. Key public health interventions should be rapidly implemented, operationalizing multi-sectoral coordination and collaboration to ensure the welfare of the society and health care workers. This includes improved access to health care facilities, access to safe water for proper hand hygiene, and access to Personal Protective Equipment (PPE) for the health care workers. Governments should enact and enforce policies that will ensure availability and affordability of key products such as masks, hand sanitizers and PPE which are essential in halting the spread of the virus. Physical distancing measures should be harmoniously enforced with public health education in order to enhance compliance and avoid resistance since social and public gatherings are common practices in African communities. Media outlets and all leaders (political, government, traditional, religious etc.) play a key role in educating the public on how to react during the outbreak due to their inherent ability to influence and reach a large number of public. They must therefore be well informed and educated in order to provide correct evidence-based information and directives. Addressing a pandemic or epidemic call for joint actions towards the interest of saving lives by practicing proven effective preventive, containment and response 
measures, leaving aside any political, religious, traditional differences and beliefs.

Preparedness plans based on lessons learned from past encounters ought to align with scenarios that include periods of either, no reported cases, sporadic cases or clustered cases and community transmission. Prior to the outbreak when no case has been reported, screening and triage protocols at country's points of entry and all levels of the health care system should be installed in addition to designating isolation areas for suspected, probable or confirmed cases. It is important to identify and address the drivers that are likely to facilitate the spread of the disease and to map vulnerable communities and locations such as high-risk elderly populations and high-density towns or cities. With reported sporadic cases, containment measures aiming at reducing the risk of amplification of the disease must be instituted rapidly. In order to meet the minimum required surge capacity, it is necessary to repurpose or build new structures and community facilities i.e. temporary field hospitals, when clustered cases are identified with evidence of community spread indicating amplification of the outbreak.

For simplicity, we categorize the response spectrum into three phases which are not distinct but rather a continuous sequence of activities; these phases include the 'containment phase', 'transition phase' and the 'mitigation phase'. Figure 3 and Figure 4 summarize the proposed models of two different response approaches that can be applied during outbreaks. Depending on the feasibility and time period of the initial response, these phases/approaches can be implemented either sequentially or concomitantly.

\section{FIGURE 3. Sequential response approach during an outbreak}

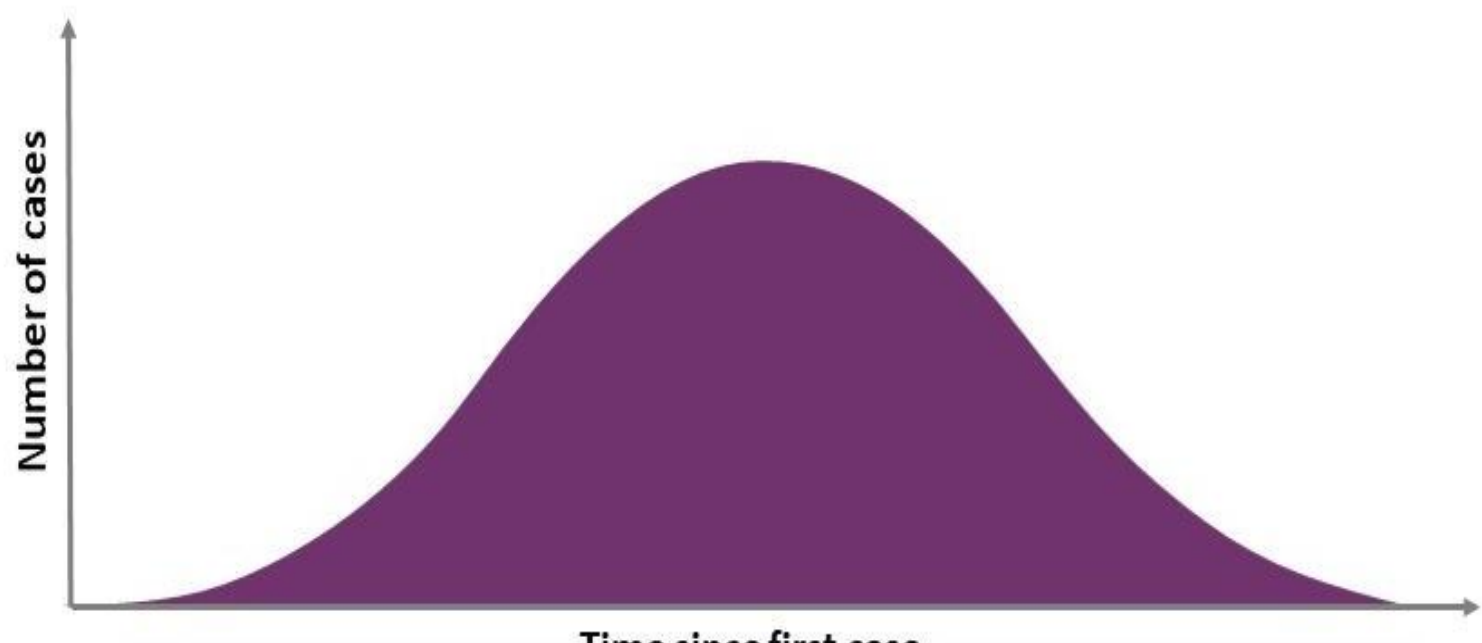

Time since first case

Containment

\section{Mitigation}




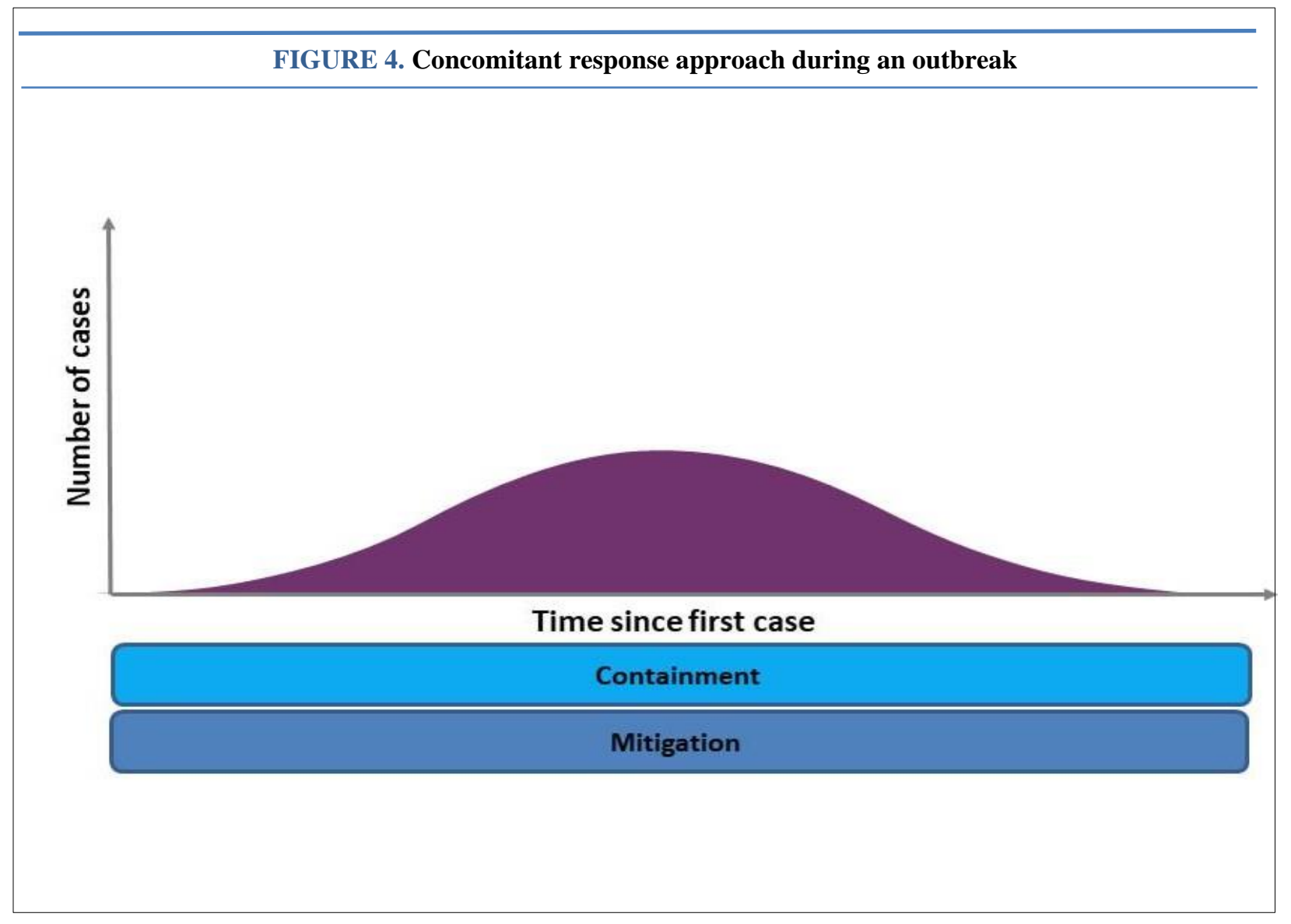

\section{The 'containment phase'}

Containment strategies are applied at the early stages (and spans to the end of an epidemic) of an outbreak aiming at confining the virus at source and avoiding spillage into the community. These strategies have to be implemented as soon as the index case is detected as seen in Figure 3 and Figure 4. It will involve case/contact tracing together with border control in order to regulate the movement of people from regions with reported cases; thus, curtailing the number of imported cases. It is crucial to allocate areas for isolation and quarantines so as to limit the circulation of the diseased in the community or within health facilities while ensuring that treatment and care is provided to the patients. Of note is that, isolation and quarantine is required not only for confirmed cases but also for persons who have been exposed to either a known or a suspected case (contacts). The recommended length of the quarantine period for COVID19 is at least 14 days, corresponding to the incubation period of 2-14 days ${ }^{11}$. Test results (where necessary) and the progress of the diseases are also determinants of the length of the isolation period. During this phase, Research \& Development (R\&D) activities aimed at gaining insight on the nature of the disease outbreak and hastening the availability of diagnostics, vaccines and therapeutics are to be strongly supported with adequate resources ${ }^{3}$. Aggressive implementation of containment strategies will halt the spread of the virus at an early stage of the outbreak reducing the necessity of up-scaling the mitigation strategies.

\section{The 'transition phase'}

The transition phase as seen in Figure 3 set-in when there is failure to contain the disease, resulting into spillage of the virus, threatening or causing sustained transmission at community level. A given threshold of successful contact tracing is essential to control early spread of the virus in the community. This threshold value can be analyzed by utilizing different statistical models that use the basic reproduction number $\left(\mathrm{R}_{0}\right)$ which is the expected number of secondary cases generated by one primary case in a susceptible population. A stochastic SARS-CoV-2 transmission model developed by Joel et al ${ }^{12}$ demonstrated that at least $70 \%$ and $90 \%$ of successful contact tracing is required to control the outbreak with a $\mathrm{R}_{0}$ of 2.5 and 3.5 respectively. Reports of community spread should alarm and 
prompt execution of mitigation strategies in addition to ongoing containment efforts. Deciding to implement the mitigation strategies might be extremely difficult for policy and decision makers especially in low-income countries as they may appear to damage the already weak economic status. Bold and well-targeted measures when implemented early and rapidly will save the economy from severe destruction and difficult as it may seem to be, the decisions have to be made quickly. However, they have to be evidence informed decisions and not panic driven decisions.

\section{The 'mitigation phase'}

As it is seen in Figure 3 and Figure 4, mitigation strategies can be applied during the amplification phase or right after detection of the index case. The goal is to reduce the disease incidence, morbidity and mortality as well as minimizing the social, political and economic impact of an epidemic ${ }^{3}$. Mitigation also serves to delay the outbreak peak thus providing time for rapid re-deployment of personnel and reallocating resources to avoid overstretching of the health care system capacity by the prolongation of the epidemic period as demonstrated in Figure $5^{13,14}$. The disease control strategies initially employed in the containment phase should be ongoing throughout this phase and may target particular cohorts with a high incidence rate that have a high likelihood of further spreading the disease into the rest of the community or to highly vulnerable cohorts ${ }^{13}$. These highly vulnerable cohorts (individuals at highest risk for severe disease and mortality) include people aged more than 60 years and those with chronic underlying conditions such as hypertension, diabetes, cardiovascular disease, chronic respiratory disease and cancer. Physical distancing measures in order to reduce human to human transmission are of essence. Studies have shown that voluntary isolation at home is a feasible strategy as compared to drastic physical distancing measures that should be reserved for severe outbreaks ${ }^{15}$. Additional measures to be undertaken will depend on the dynamics of the outbreak; theses may include non-pharmacological interventions such as hand hygiene, respiratory hygiene, face mask ordinances, or strict physical distancing measures. Pharmacological interventions will aim at either treatment or prevention of the disease. These include specific treatments, prophylaxis or vaccinations when available. Provided that pharmacological interventions are of value, non-pharmacological interventions are the mainstay due to lag in development of tests, therapeutics and vaccines.

\section{FIGURE 5. Goals of Community Mitigation}

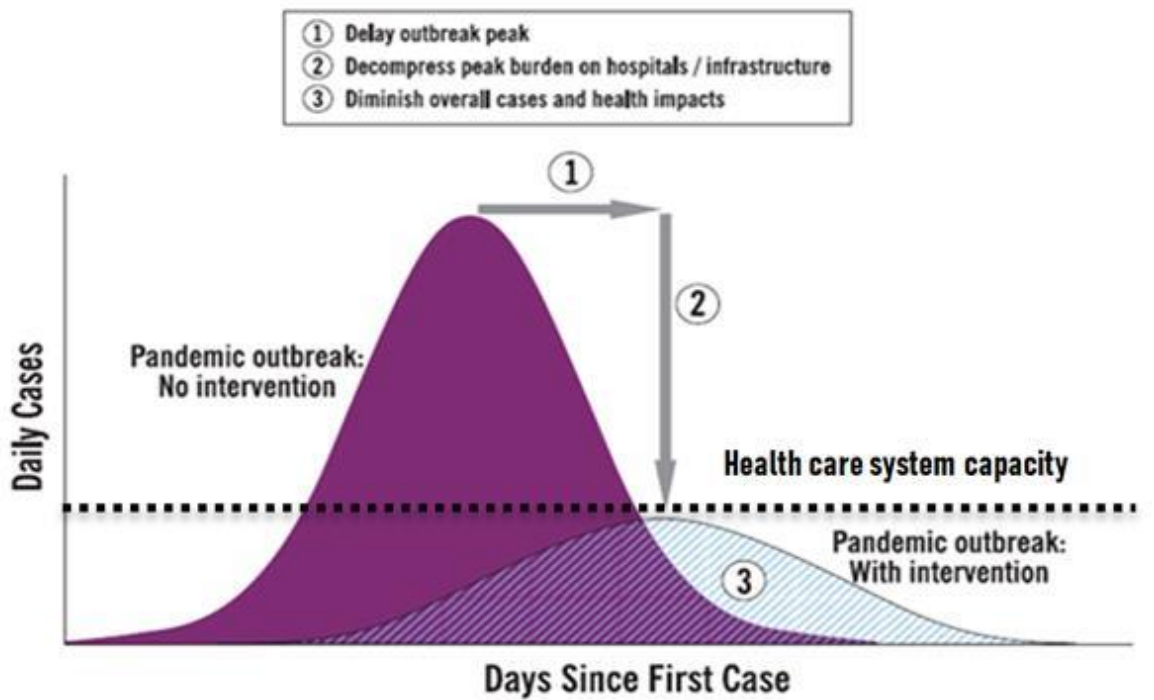

Adapted from: CDC. Interim pre-pandemic planning guidance: community strategy for pandemic influenza mitigation in the United States — early, targeted, layered use of non-pharmaceutical interventions. https://stacks.cdc.gov/view/cdc/11425. 
The value of early up-scaling of mitigation strategies Several studies have assessed the effectiveness of implementing multiple interventions in reducing the rate of disease transmission during outbreaks. Reduction of the effective reproduction number from approximately 3.0 to to 1.0 in less than one month period following implementation of cordons sanitaire, traffic restriction and home quarantine in controlling the COVID-19 outbreak in Wuhan, China has been demonstrated ${ }^{16}$. Assessment of the intensity of the 1918-1919 influenza pandemic showed that cities in which multiple interventions were implemented at an early phase had peak death rates of approximately $50 \%$ less as compared to their counterparts ${ }^{17}$. In addition to the layered and early implementation of public health interventions, sustained interventions are strongly associated with a lowered and delayed peak of mortality ${ }^{18}$.

A common finding in these studies suggest that early implementation of multiple sustained interventions has a promising outcome on responding to epidemics. These findings provide evidence to the gentleness of the curve in (Figure 4) that corresponds with the concomitant approach in responding to an epidemic. Although less feasible as compared to the sequential approach (Figure 3), the concomitant approach has to be advocated whenever failure to contain the diseases is anticipated.

\section{Screening during different phases of the outbreak}

The real-time reverse transcriptase-polymerase chain reaction (rRT-PCR) test used for qualitative detection of nucleic acid of SARS-CoV-2 from nasopharyngeal swabs has typically been used to confirm the clinical diagnosis of COVID-19 ${ }^{19}$. However, rapid diagnostic tests (RTDs) are of particularly interest due to the speed in obtaining test results and less reliance on laboratory-based services especially in countries with reduced laboratory diagnostic capacity. Nonetheless, based on current evidence, the WHO does not recommend the use of COVID-19 antigen-based RDTs for clinical decision-making due to lack of validation of the rapid test kits with an expected low test sensitivity ranging between $34 \%$ and $80 \%$.

Since tests with high sensitivity are required at the screening phase, in the absence of highly sensitive tests, parallel testing involving the use of two or more tests applied to a patient at the same time can be employed in order to increase test sensitivity ${ }^{21,22}$. High levels of test sensitivity are essential since missing cases can have devastating consequences. Caution should also be taken in declaring cured cases in the face of tests with poor specificity which is the ability of a test to correctly classify an individual without a diseased. This can be achieved by applying serial testing in order to improve the test specificity ${ }^{22}$.

\section{Testing in containment phase}

Target screening approach which involves testing persons who meet the given standard case definition is economic and may be preferred. We presume that at the beginning of the outbreak the prevalence of the diseases in the community is low, resulting into a subsequent low Positive Predictive Value (PPV) of a given screening test which is the probability that subjects with a positive screening test truly has the disease of interest ${ }^{14}$. Applying mandatory mass screening in a population with low disease prevalence will result into large numbers of false positives which will be a waste of time and resources especially in resource constrained areas. Such resource would rather be reallocated to prioritize core preparedness activities for the mitigation phases including improving diagnostic and treatment capabilities, repurposing facilities to meet the surge capacity, training and ensuring availability of PPE for health care providers.

\section{Testing in mitigation phase}

Mandatory mass screening approach will most likely be productive during the amplification phase of the pandemic. We presume that the prevalence of the disease in the community at this phase is high; thus, a given screening test will yield a high PPV with subsequent lesser number of false positives $^{23}$. Mass community testing is important since, mildly symptomatic and asymptomatic cases will be identified, isolated and treated; hence limiting the disease transmission.

\section{RECOMMENDATIONS}

In summary, the following action points are recommended:

- Countries should seize COVID-19 pandemic as an opportunity to invest adequately in sustainably strengthening their health systems' capacities for preparedness and response against public health threats.

- Countries and the region should establish and continuously update national and regional teams of experts ready for rapid deployment during outbreaks.

- Responsible national and regional authorities should provide resources for rapid activation of Research \& Development activities to address the Pandemic.

- Continuous education on personal and environmental interventions such as personal hygiene and large-scale disinfection efforts taken during the outbreak should be maintained as routine practices even after the pandemic to avoid a secondary peak and subsequent outbreaks.

- Countries must rapidly develop and institute policies facilitating implementation of containment strategies to stop early progression of the pandemic in order to avoid social and economic consequences.

- Countries must implement mitigation measures early (at the earliest signal of sustained community spread), in order to prevent prolonged lockdown, save lives and reduce related economic hardship. 


\section{CONCLUSION}

COVID-19 pandemic has already affected millions of people worldwide. Due to the alarming trends of the disease spread particularly in EAC partner states, decision makers should work together to scale up containment and mitigation strategies in order to slow the spread of the disease across the region. Quarantine, lock down and travel restrictions must be enforced at the earliest signals of community spread while maintaining personal measures like proper hand hygiene and avoidance of crowds and congregations. Leaders must adhere to WHO guidelines, disseminate evidence-based messages and seek any clarifications and guidance from their national or regional experts. COVID-19 respects neither borders nor political, religious or traditional beliefs. Leaders must avoid issuing wishful messages based on their own opinion or beliefs as many lives may be at stake if conflicting messages are issued. Let us be educated by current knowledge and follow scientific preventive, containment, and mitigation measures. Current interventions must be sustained not only to avoid a secondary peak of the outbreak, but also to allow the culture of hygiene that may prevent future threats. The current COVID-19 pandemic is an opportunity to revive hygienic culture, strengthen health systems and invest in sustaining the capacities, ready to respond to both the current and future outbreaks.

\section{REFERENCES}

1. WHO. WHO | SARS (Severe Acute Respiratory Syndrome). Who.int. https://www.who.int/ith/diseases/sars/en/. Accessed April 14, 2020.

2. CDC. 2014-2016 Ebola Outbreak in West Africa | History | Ebola (Ebola Virus Disease) $\mid$ CDC. Cdc.gov.

https://www.cdc.gov/vhf/ebola/history/2014-2016-outbreak/index.html. Published 2019. Accessed April 14, 2020.

3. World Health Organization. Managing Epidemics: Key Facts About Major Deadly Diseases. 1st ed. Luxembourg: World Health Organization; 2018.

4. WHO. Novel Coronavirus (2019-nCoV) SITUATION REPORT - 1. Who.int. https://www.who.int/docs/defaultsource/coronaviruse/situation-reports/20200121-sitrep-1-2019-ncov.pdf. Published 2020. Accessed April 14, 2020.

5. The World Bank Group. Understanding the Coronavirus (COVID-19) pandemic through data | Universal Health Coverage Data | World Bank. Datatopics.worldbank.org. http://datatopics.worldbank.org/universalhealth-coverage/covid19/. Published 2020. Accessed April 20, 2020.

6. WHO Director-General's opening remarks at the media briefing on COVID-19 - 3 March 2020. Who.int.

https://www.who.int/dg/speeches/detail/who-director-general-s-openingremarks-at-the-media-briefing-on-covid-19---3-march-2020. Published 2020. Accessed April 6, 2020.

7. Khafaie M, Rahim F. Cross-Country Comparison of Case Fatality Rates of COVID-19/SARS-COV-2. Osong Public Health Res Perspect. 2020;11(2):74-80. doi:10.24171/j.phrp.2020.11.2.03

8. Disease Control Priorities. 3rd ed. Washington (DC): The International Bank for Reconstruction and Development / The World Bank; 2017.

9. Bedford J, Enria D, Giesecke J et al. COVID-19: towards controlling of a pandemic. The Lancet. 2020;395(10229):1015-1018. doi:10.1016/s0140-6736(20)30673-5

10. Nzietchueng S, Kambarage D, Rwego I et al. Post-Ebola Awakening: Urgent Call for Investing in Maintaining Effective Preparedness Capacities at the National and Regional Levels in Sub-Saharan Africa. East African Health Research Journal. 2019;3(1):79-84. doi:10.24248/eahrj.v3i1.602
11.Linton N, Kobayashi T, Yang Y et al. Incubation Period and Other Epidemiological Characteristics of 2019 Novel Coronavirus Infections with Right Truncation: A Statistical Analysis of Publicly Available Case Data. J Clin Med. 2020;9(2):538. doi:10.3390/jcm9020538

12. Hellewell J, Abbott S, Gimma A et al. Feasibility of controlling COVID19 outbreaks by isolation of cases and contacts. The Lancet Global Health. 2020;8(4):e488-e496. doi:10.1016/s2214-109x(20)30074-7

13. CDC. Interim pre-pandemic planning guidance: community strategy for pandemic influenza mitigation in the United States - early, targeted, layered use of nonpharmaceutical interventions. https://stacks.cdc.gov/view/cdc/11425. Published 2017. Accessed April 7, 2020.

14. Anderson R, Heesterbeek H, Klinkenberg D, Hollingsworth T. How will country-based mitigation measures influence the course of the COVID19 epidemic?. The Lancet. 2020;395(10228):931-934. doi:10.1016/s0140-6736(20)30567-5

15. Fong M, Gao H, Wong J et al. Nonpharmaceutical Measures for Pandemic Influenza in Nonhealthcare Settings-Social Distancing Measures. Emerging Infect Dis. 2020;26(5). doi:10.3201/eid2605.190995

16. Pan A, Liu L, Wang C et al. Association of Public Health Interventions With the Epidemiology of the COVID-19 Outbreak in Wuhan, China. JAMA. 2020. doi:10.1001/jama.2020.6130

17. Hatchett R, Mecher C, Lipsitch M. Public health interventions and epidemic intensity during the 1918 influenza pandemic. Proceedings of the National Academy of Sciences. 2007;104(18):7582-7587. doi:10.1073/pnas.0610941104

18. Markel H, Lipman H, Navarro J et al. Nonpharmaceutical Interventions Implemented by US Cities During the 1918-1919 Influenza Pandemic. JAMA. 2007;298(6):644. doi:10.1001/jama.298.6.644

19. Wang D, Hu B, Hu C et al. Clinical Characteristics of 138 Hospitalized Patients With 2019 Novel Coronavirus-Infected Pneumonia in Wuhan, China. JAMA. 2020;323(11):1061. doi:10.1001/jama.2020.1585

20. WHO. Advice on the use of point-of-care immunodiagnostic tests for COVID-19. Who.int. https://www.who.int/newsroom/commentaries/detail/advice-on-the-use-of-point-of-careimmunodiagnostic-tests-for-covid-19. Published 2020. Accessed April 15, 2020.

21. Parikh R, Mathai A, Parikh S, Chandra Sekhar G, Thomas R. Understanding and using sensitivity, specificity and predictive values. Indian J Ophthalmol. 2008;56(1):45. doi:10.4103/0301-4738.37595

22. Franco F, Di Napoli A. Evaluation of diagnostic tests in parallel and in series. Giornale di Tecniche Nefrologiche e Dialitiche. 2016;28(3):212215. doi:10.5301/gtnd.2016.15992

23. Tenny S, Hoffman M. Prevalence. Ncbi.nlm.nih.gov. https://www.ncbi.nlm.nih.gov/books/NBK430867/. Published 2020. Accessed April 9, 2020

\section{Disclaimer}

The authors' views and the opinions expressed in this article do not necessarily reflect the official views or positions of the institutions of affiliation.

\section{Peer Reviewed}

Competing Interests: None declared.

Received: 12 Apr 2020; Accepted: 23 Apr 2020.

Cite this article as: Kitua DW, Kitua AY. COVID-19 Awakening: Preparedness, Readiness and Response during the pandemic. E Afr Sci. 2020;1(2):1-8. http://doi.org/10.24248/EASci-D-20-00006

(C) Kitua et al. This is an open-access article distributed under the terms of the Creative Commons Attribution License, which permits unrestricted use, distribution, and reproduction in any medium, provided the original author and source are properly cited. To view a copy of the license, visit http://creativecommons.org/licens- es/by/4.0/. When linking to this article, please use the following permanent link: http://doi.org/10.24248/EASci-D-20-00006 